\title{
ASSESSING ORGANIZATIONAL CAPACITY AND SUSTAINABILITY OF A PARTNERSHIP: THE FUTURE OF CERIS
}

by

\author{
Stephen Cohen \\ Graduate Diploma Community Economic Development \\ Concordia University, 2007 \\ BA Specialization Human Relations \\ Concordia University, 2006
}

\begin{abstract}
A Major Research Paper
presented to Ryerson University

in partial fulfillment of the requirements for the degree of
\end{abstract}

\author{
Master of Arts \\ in the Program of \\ Immigration and Settlement Studies
}

Toronto, Ontario, Canada, 2012

(C) Stephen Cohen 2012 


\section{Author's Declaration}

I hereby declare that I am the sole author of this Major Research Paper. This is a true copy of the MRP, including any required final revisions, as accepted by my examiners.

I authorize Ryerson University to lend this MRP to other institutions or individuals for the purpose of scholarly research.

I further authorize Ryerson University to reproduce this MRP by photocopying or by other means, in total or in part, at the request of other institutions or individuals for the purpose of scholarly research.

I understand that my MRP may be made electronically available to the public. 


\title{
ASSESSING ORGANIZATIONAL CAPACITY AND SUSTAINABILITY OF A PARTNERSHIP: THE FUTURE OF CERIS
}

(C) Stephen Cohen 2012

\author{
Master of Arts \\ Immigration and Settlement Studies \\ Ryerson University
}

\begin{abstract}
This case study explores the sustainability and continuation of a centre of research and knowledge transfer around issues related to immigration and settlement. It discusses the institutional context of CERIS and the various policy and practice relevant uses of academic research. It draws on literature and theory about organizational capacity in nonprofit organizations and academic partnerships. The case assesses whether CERIS, has the capacity to renew and continue functioning beyond its funding mandate. Data was primarily collected from in-depth interviews with key stakeholders. The results of this paper indicate both opportunities and challenges for a renewed CERIS-like organization to continue functioning in the environment. The study has implications generally for the sustainability of collaborative partnerships.
\end{abstract}

Key Words: CERIS, Organizational Capacity in Nonprofits, Partnership, Collaboration, Expert Knowledge, Immigration Research, Knowledge Mobilization 


\section{Acknowledgements}

I would like to express my sincerest thank you to my academic advisor and research supervisor, Prof. Agnes Meinhard. I am gratefully for the support, patience and insight, that Agnes provided me this past year and specifically for this study. Her invaluable expertise and knowledge in the subject area and academic advice was fundamental to the completion of my research.

I would also like to thank to Prof. John Shields, the second reader of this research for providing me with his insightful comments and suggestions.

Special thanks to Prof Mehru Ali who helped to provide me with direction and gave me essential advice that allowed me to advance the research.

My sincere gratitude and appreciation goes to the Yuko Sorano and Raymond Hyma, current staff members of CERIS. Their knowledge, positive attitudes and support allowed me to move forward with this project. Also, thank you to the Board of Directors at CERIS, whom granted me permission to undertake the study.

Lastly, I would like to acknowledge the patience and generosity of the research participants. While I cannot name the individuals for confidentiality purposes, they know who they are. Their insights and willingness to share with me their opinions about CERIS was a testament to, not only their commitment to the organization and the community of researchers, but also their commitment to helping out a graduate student. Thank you.

This research could not have been possible without the contributions of aforementioned people. 


\section{Table of Contents}

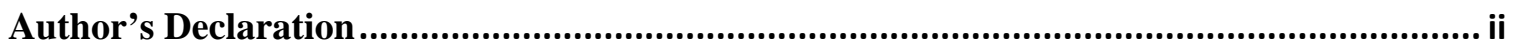

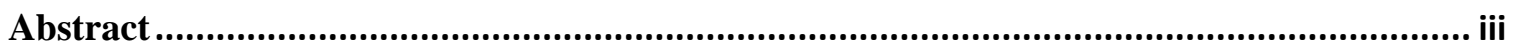

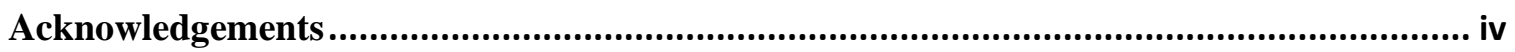

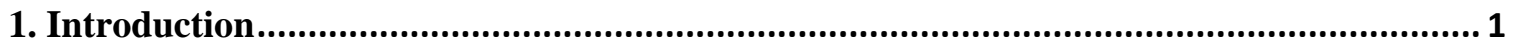

1.1 Background and Research Question...................................................................... 1

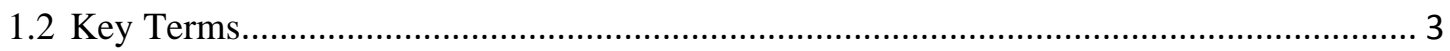

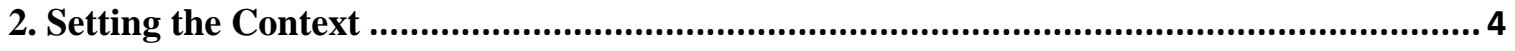

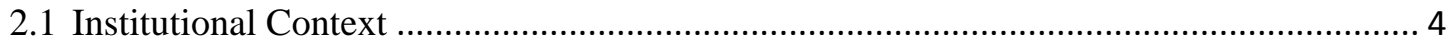

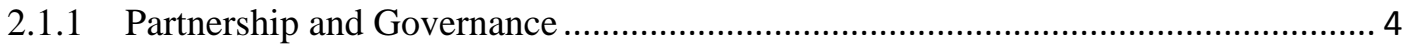

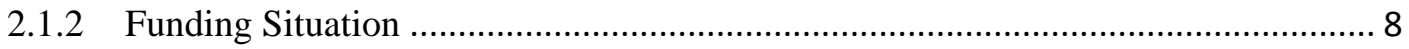

2.1.3 The Value of CERIS; Achievements and Successes ............................................ 9

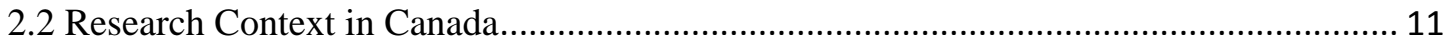

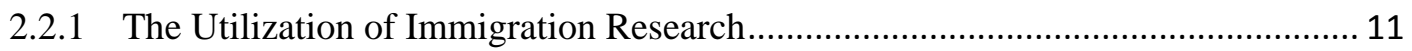

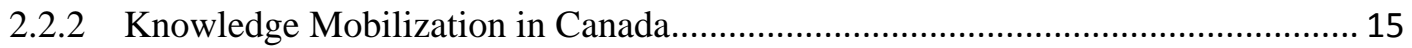

2.2.3 Non-Profit Funding Context for Research..................................................... 18

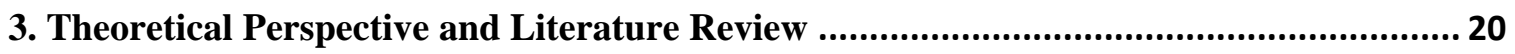

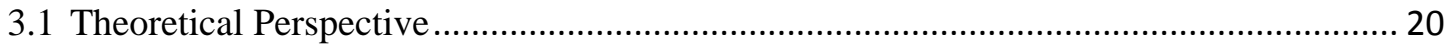

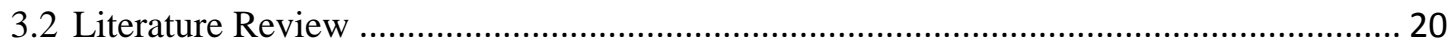

3.2.1 Organizational Capacity in Non-profit Organizations ......................................... 20

3.2.2 Understanding Capacity in Nonprofit Organizations ........................................ 21

3.2.3 Core Competencies: Financial \& Human Resources ............................................. 24

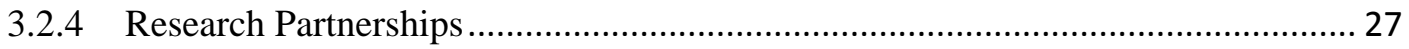

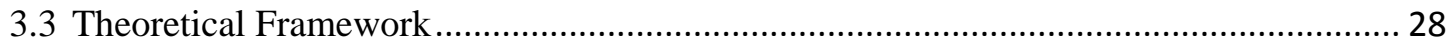




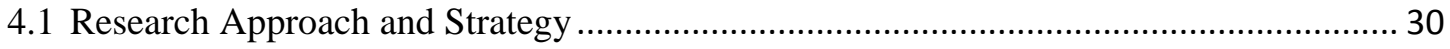

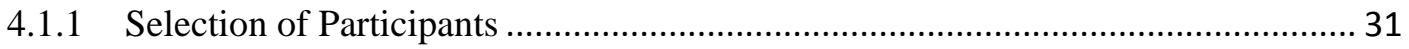

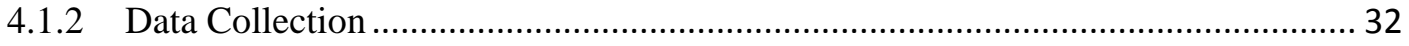

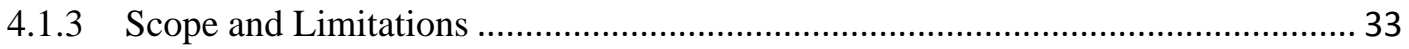

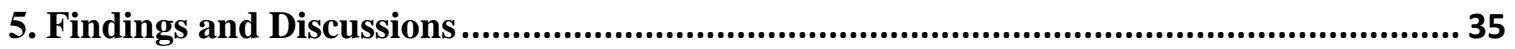

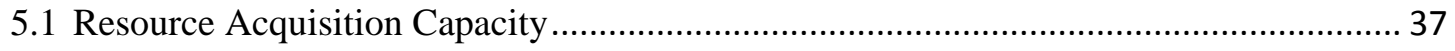

5.1.1 The Challenge of Core/Institutional Funding .................................................. 37

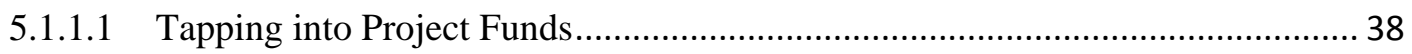

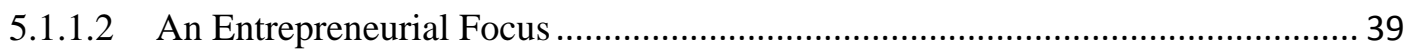

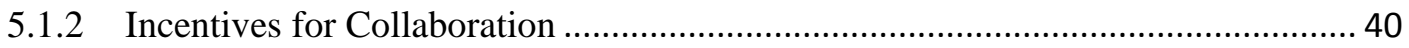

5.1.3 Community Organizing/Bottom-up Approach and Sustained Participation............ 41

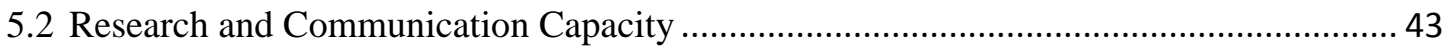

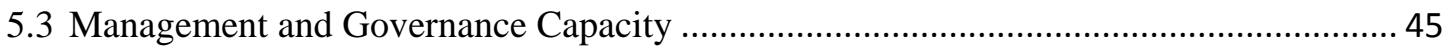

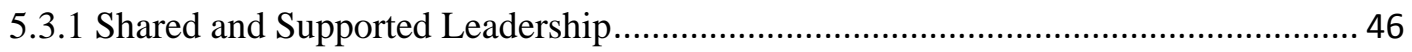

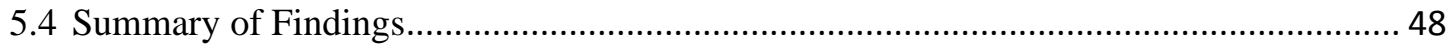

5.5 Implications for the Sustainability of Partnership Model ............................................. 49

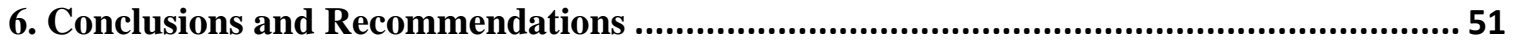

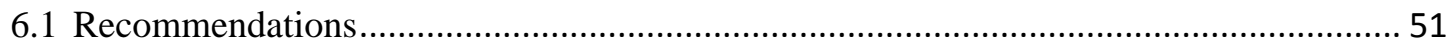

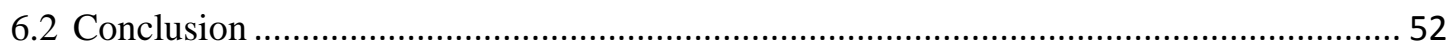

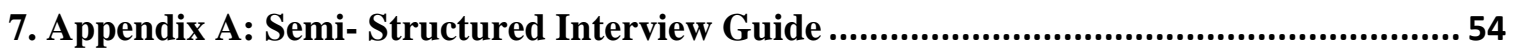

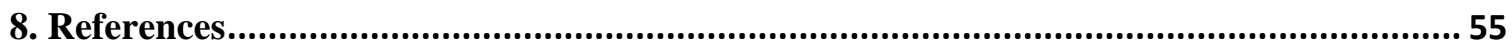




\section{Introduction}

\subsection{Background and Research Question}

This research is a case study about the sustainability and continuation of a centre of research and knowledge transfer around issues related to immigration and settlement. CERIS - The Ontario Metropolis Centre is an organization that produces research and facilitates the various uses of academic knowledge on immigration across sectors of society in Ontario. It is one of five research centres that are a part of the Metropolis Project. This Project is a partnership between government, academia and community groups, established in 1995, with a mandate to develop public policy research to guide policy decisions around immigration and settlement (SSHRC, 2000). The Metropolis Project has played a vital role in supplying governments, academia and community groups with an array of quality research projects and knowledge exchange opportunities (SSHRC, 2000; 2008; CIC, 2006; Clippingdale; 2006). It has recently finished a 15-year funding program administered by the Social Science and Humanities Research Council (SSHRC) on behalf of Citizenship and Immigration Canada (CIC) and other federal government ministries, with no additional long term funding commitments.

The goal of this study is to examine the organizational capacity and ultimately sustainability of a nonprofit collaborative partnership model. It intends to further the discussion on organizational planning with respect to the ability of CERIS to renew itself and adapt to the environment without the Metropolis Project funding and infrastructure.

The methodology being used is a case study. As such, the information has been obtained from various sources including peer-reviewed journals, memorandums of 
agreements, evaluations, annual reports, meeting minutes and in-depth interviews with key stakeholders.

This study will provide an overview of CERIS from a historical perspective and refer to its shared governance, funding situation, successes and challenges. It will discuss the context of the funding environment for both nonprofit organizations and also for social science research in Canada. My research will draw on organizational theory and a combination of existing organizational capacity and human resource capacity frameworks. Finally, it will describe academic partnerships and the emerging field of knowledge mobilization. I have developed a framework to explore the primary research question: How can CERIS continue to create and share knowledge, and influence policies and practices concerning immigration beyond its current funds, ending March 31, 2013?

Subsidiary questions that have addressed the primary research question are: What is an effective framework to measure CERIS's organizational capacity? What are the strengths and proven ability of CERIS to connect with its partners? What are the major gaps in relation to CERIS' ability to continue? What are specific requirements and needs for the organization to continue? And, what are the opportunities and challenges for CERIS moving forward?

The findings point to several uncertainties about sustaining a collaborative institution and about functioning with a decreased capacity. There are however, several opportunities presented about continuing knowledge mobilization activities. This will be explored further in this document. The research may also provide selective insights that are transferable other types of nonprofit organizations dealing with unstable funding. 


\subsection{Key Terms}

Before moving on, there are a few terms that are used in this study that I would like to clarify for the reader. Organizational stakeholder(s) in this study refers to anyone who is affiliated with CERIS. This can include: staff, researchers with a formal position with CERIS (past or present), researchers who are recipients of CERIS funding, Metropolis staff, community groups, government officials, other nonprofit organizations and graduate students who identify as such. Nonprofit organizations are used to refer to organizations that are service providing, nongovernmental and have an independent governance board. They can be commonly identified as serving the public or their members, and utilizing an institutional form in which profits cannot be distributed to its owners or directors (Hall et al., 2005). Knowledge mobilization is a series of strategies that build ongoing and systematic exchange of social science knowledge between academic and non-academic stakeholders (Anisef et al., 2007). There is no consensus definition of expert knowledge. In this case, it is differentiated from other types of knowledge because its generated by academics. As such, it has two overarching features that distinguish it; the institutional contexts in which it is created and substantive and procedural requirements, which meet theoretical or conceptual standards of coherence (Boswell, 2009). 


\section{Setting the Context}

\subsection{Institutional Context}

In 1996, CERIS - The Ontario Metropolis Centre was established as part of the Metropolis Project, along with four other university-based research centres across Canada. The original objectives of CERIS were to: 1) to create a community dedicated to research on immigration and settlement; 2) to promote innovative, multidisciplinary research on the integration of immigrants into Canada's economic, social, political and cultural life; 3) to create sustained, collaborative research programs involving academics and policy-makers concerned with immigration issues; 4) to provide training opportunities for students interested in immigration issues; and 5) to disseminate research broadly to stimulate policy development and debate among the broad general public (CERIS , 2003). CERIS has developed ways to facilitate the use of research in decision making and promote knowledge exchange between researchers and its partners (SSHRC, 2000).

\subsubsection{Partnership and Governance}

CERIS represents a unique partnership between government, academics and community groups with the ultimate goals of improving policies for managing immigration and diversity. It is a joint initiative from academic partners; Ryerson University, University of Toronto and York University and community partners; Ontario Council of Agencies Serving Immigrants, the Community Social Planning Council of Toronto, and the United Way of Greater Toronto. The government contribution included the provision of funding, providing direction for research focus, and the former Metropolis Secretariat housed within CIC. The Secretariat facilitated the exchange of information between the research 
centres and policy makers. These groups are represented in the organization's governance structures.

The primary responsibilities of members of the governance committee are related to its fiduciary (legal), programmatic and financial well being. Subsidiary boards, councils and committees have been developed and restructured to carry out the organization's mission and activities. These committees include; executive, management, data management, partnership advisory and organizational development (CERIS Governance Policy Documents, 2005).

According to literature on nonprofit organizations and CERIS in particular, strategic and structural positioning of partners can result in an uneven and tiered set of partnering relationships, especially when relationships are primarily organized around funding contracts (Eakin, 2002; Blue Ribbon, 2006; Shields, 2007). The clearly articulated roles for all partners however allowed for CERIS to successfully maneuver through the distribution of unequal resources by all parties, albeit with challenges (Interview \#3, May 30, 20121).

The multiple roles and representation of partners within the governance, management and operations of CERIS results in their increased engagement and interaction. The reliability established through the governance structure mitigates some aspects of this unequal power distribution. In CERIS's case, the structure provided unique benefits for the government, the partner universities, individual academics and their community partners (Shields \& Evans, 2008). The governance structure lends

1 Research participants have first hand knowledge and intimate experience working with CERIS and are representative of various roles past and present such as CERIS leadership and former staff, government stakeholders, community-based stakeholders and academic stakeholders. 
credibility to all partners, especially funders, that the decisions made are in the best interests of the organization. The prominence of academia also lends credibility to the research that is generated through the network. There are shared decision making mechanisms, like adjudication processes, which included a community influence. The appreciation of viewpoints from the full range of partner institution and representatives influenced the research agenda and enabled interest, influence and buy-in of stakeholders.

This collaborative governance structure also has implicit challenges. It has a bureaucratic framework, which can slow down decision-making (Townhall Meeting Report, 2012). The interests of the principle funders dominated and influenced actions at times to suit their agendas (Interview \#7, June 28, 2012). In the Second Phase, the government partners called for an increase of pan-Canadian research, which altered the focus of the original initiative. The tri-university partnership and the relationship between the universities is complex and various tensions also emerged over time. There were occasions where CERIS proved vulnerable to disengagement of partner institutions which curtailed organizational advancement (Interview \#6, June 13, 2012). As a collaborative initiative, the organization is susceptible to a lack of ownership from any one partner. Rummens (2012), highlights the importance of interaction and the exchange of information within the structure of the governance board and its ongoing activities for knowledge mobilization. She states that this is fundamental to permit the ongoing and systematic exchange of policy and practice relevant knowledge among academic and non-academic stakeholders.

A more detailed look at the historical rationale for involvement of all parties is essential in understanding the organizational function. The federal government sought to 
benefit from universities, by pooling their talents and resources to promote scientific, policy-driven and cross-disciplinary research on immigration in Canada. Specifically they were interested in research that could directly inform policymaking and government programming (Shields \& Evans, 2008). They provided significant financial resources to enable the development and functioning of the Centres of Excellence and the Secretariate housed within CIC. This drew the resourcing of university partners. This also fit nicely into SSHRC's mandate of advancing academic research capacity, fostering primary research, graduate student training, as well as knowledge mobilization and knowledge transfer (Shields \& Evans, 2008).

Universities took on the initiative, because they were being pushed to have their research produce discernable benefits for society (Metropolis, 2006). The institutions were able to increase their research profiles and take advantage of the financial opportunity presented to them. In addition, the Metropolis Project has an international component and both the larger project and CERIS have developed a positive national and international reputation.

Individual academics had increased access to research funds, publication opportunities, government stakeholders, immigrant communities and community-based organizations. It has also connected and created an avenue for faculty to be engaged in cross disciplinary research projects and connected faculty and academics to other knowledge producers and consumers. They had opportunities to influence policy decisions, attend and present at networking events, conferences and seminars. Through arrangements with the universities, invested academics potentially had course release time to focus on their research and responsibilities to CERIS. They were part of an 
emerging community and affiliated with a recognized and credible institution by all three levels of partners. Certainly, CERIS affiliation was generally beneficial to academic career trajectories.

Community partners had their own rationale for involvement and sought to benefit from participation in the research network through identifying research priorities, expanding their own networks and increasing advocacy support. The networks provided formal and informal opportunities to connect with relevant stakeholders to enhance various aspects of individuals' work and organizations' agendas. Further, the research generated through CERIS provided a strong foundation for their advocacy work (Interview \#1, May 29, 2012).

\subsubsection{Funding Situation}

Metropolis Centres were initiated at universities across Canada in the cities with the largest immigrant-receiving populations. In 1995, the CIC through SSHRC put out a request for proposals. The Ontario proposal by Ryerson University, University of Toronto and York University was successful and received funding for a five-year period to develop the Ontario Centre of Excellence, CERIS. Funding was extended for two subsequent 5-year periods following positive evaluations, consultations and applications to the federal government partners. The exchange was critical to its renewal efforts and influenced the scope of work and direction of the organization for each funding period.

One of the greatest institutional strengths of CERIS has been its ability to leverage funds, acquire resources from various partners and attract funding external to the Metropolis budget (CERIS, 2003; Interview \#3, May 30, 2012). Rummens (2012) articulates that CERIS permits sharing resources to address pressing issues around 
migration, resettlement and diversity. The partnerships allow for leveraging of resources, both monetary and in-kind contributions. From an annual grant of $\$ 307,000$, universities contributed an additional \$233,000 in funds, course release time and other contributions such as office space. In addition, CERIS affiliated researchers leverage millions of external research dollars each year. The revenues captured by CERIS are far greater than each partner's contribution (CERIS Annual Report 2012).

By 2011, it was announced that after 15 years the funding for the Metropolis Project would not be renewed. This would subsequently dismantle the Metropolis Secretariat in Ottawa and close the regionally and university-based research centres, of which there were now five (Keung, 2012). This signifies the end of the governance structure that facilitated the partnership, enabled successful knowledge creation and exchange and managed the distribution of resources.

\subsubsection{The Value of CERIS; Achievements and Successes}

Over the years, it has been recognized that CERIS has been successful at achieving many of its original objectives. It has also significantly influenced the current landscape of immigration research in Ontario. The present institutional reality of CERIS is not that of a victim of government funding cuts, but the winding down of a successful initiative in its current form (Interview \#2, May 23, 2012). No other Centres of Excellence funded through SSHRC had been successfully renewed for a third term, as was the case for CERIS and the Metropolis Project (Shields \& Evans, 2008). The objectives have been met in several ways including; the quality and quantity of CERIS outputs; the establishment and expansion of affiliate research community; the increased attention to research on immigration from various sectors of society; and the development of the 
Master's of Arts in Immigration and Settlement Studies at Ryerson University. It has been a catalyst for immigration research in Ontario.

CERIS's research and communication generated through its community of networked knowledge producers and consumers has been its fundamental strength. In his study of funding for organizations that influence policy (policy actors), Mandeville (2007) concludes, the majority of funding goes to supporting policy actors' ability to produce and convey information. In CERIS's case, this is greatly enhanced by its housing within an academic institution and its prioritization of academic research. CERIS outputs over the last 15 years include; academic publications in peer reviewed journals, books, book chapters, working papers, policy matters, etc. As Shields and Evans (2008) highlight that a multi-layered range of networking and dissemination activities are carried out by CERIS. This includes annual policy research symposiums, graduate student conferences, seminar series. Metropolis conferences and other conference presentations, media presentations, poster presentations, accessible data, website updates, a resource centre, listervs, and various engagements with policymakers and community groups (NGO’s). Further CERIS has provided research funds, research awards, internships and experiences towards training a new generation of researchers. In an evaluation of the Metropolis Project, Clippingdale (2006) found general satisfaction of Metropolis products and Centre activities for those who assessed and used them.

In addition to outputs, CERIS emphasized the value of research, bringing likeminded people together and recognizing diverse stakeholder engagement in all aspects of research. Its commitment to community involvement was greatly appreciated and earned respect from all stakeholders (Interview \#1, May 29, 2012). 
CERIS established a community through its affiliation system. According to the CERIS Affiliation Policy (2005), having affiliation means being an active membership in a research community. In 2002, there were 240 affiliates (The First 6 Years) and by 2011, this grew to 381 affiliates (CERIS Annual Report draft, 2012). This means, a community of individuals engaged in immigration research either in producing knowledge, consuming research or sharing first and second hand experiences through involvement in research projects. The quality and quantity of immigration themed research has increased exponentially through CERIS affiliates. The affiliation system also maintained progressive involvement within the institution and sustained growth of the community.

The development of the Master of Arts in Immigration and Settlement Program at Ryerson University is another example of an objective met by CERIS. It has changed the academic landscape of research in immigration and settlement in Ontario. CERIS facilitated many of the immigration-specific research experiences of the multidisciplinary Ryerson-based researchers associated with the program. The program has inspired hundreds of graduate students to focus on various aspects of immigration research. Further, immigration and settlement has become a central research theme at Ryerson University, including the establishment of the aforementioned Ryerson Centre for Immigration and Settlement

\subsection{Research Context in Canada}

\subsubsection{The Utilization of Immigration Research}

Understanding the purpose of academic research is critical to examining its uses and relationship to practitioners and policy-makers. Weiss (1979) differentiates between two 
functions of academic work: problem solving meant for direct application and enlightenment, in which generalizations help shape the way people think about issues (as cited by Paris, 2011). In the case of the former, research can play a pivotal role in developing policies, learning about the implications of migration, and understanding the new realities facing our cities, communities, citizens and noncitizens.

Canada's Immigration and Refugee Protection Act (IRPA) has a robust purview that states its intention to; support the development of a strong and prosperous Canadian economy; see that families are reunited in Canada; and grant, as a fundamental expression of Canada's humanitarian ideals, fair consideration to those who come to Canada claiming persecution (IRPA, 2002). The IRPA functions as a skeletal framework, setting out the broad terms of immigration policy. The details are reconfigured through regulatory changes, new programs and various policies aimed at maximizing economic benefits of the program (Kelly \& Trebelock, 2010). Since IRPA's implementation, the government has acquired increased decision-making power and flexibility regarding immigration policies (CIC, 2012).

Research and advocacy functions contribute to the larger issue of policy development, visible when Canadian governments at the federal and provincial levels seek to build their respective policy capacities through network and policy community building (Shields \& Richmond, 2004). The Metropolis Project was motivated by a need to develop a system for generating and using knowledge in the formulation of public policy on immigration and integration (Anisef, et al., 2007). As stated by CIC, "the successful integration of immigrants is crucial to Canada's social and economic wellbeing... We have much to gain from exploring the effects of migration on the strength of 
our economy, the security of our nation, and the relationships between different cultures living side by side within our borders” (CIC, 2008, n.p.). Literature and government publications show that the Canadian government increasingly recognizes the need to use evidence-based research in their policy decisions (Cohn; 2006; Shields, 2007; CIC, 2008; Boswell, 2009;).

Given the changing economic situation and an increasingly complex public policy making process, it is in the interests of all to include academia as a vital partner to governments. Academia can provide; sophisticated research and economic modeling, best practices, service as technical assistance centers, and conveners of forums and conferences with stakeholders (Gatta \& McCabe, 2008). Dukeshire and Thurlow (2002), outline four ways in which research can inform policy: recognizing problems and identifying issues; understanding key issues; supporting a selected plan of action; and evaluating and monitoring progress.

In contrast, other researchers believe the process of policy development is much more complex. There are extensive practical and ideological barriers that prohibit outside influence in shaping policy (Cohn, 2006; Shields 2007). Boswell conceptualizes a theory for three different political uses of expert knowledge; instrumental, legitimizing and substantive. The first, a rarity, describes research that is instrumental to the development a new policy. The second and more common usage is that an organization can enhance its legitimacy and bolster its claim to resources or jurisdiction over policy areas. This use creates confidence that decisions will be well founded, especially when an institutional culture places value on knowledge such as the case with government bodies. Substantive use is when expert knowledge lends authority to particular policy positions. 
Anisef et al., (2007); Evans and Shield (2008); and Rummens (2012) examine the intricacies of knowledge mobilization and the ability for government to unlock the potential of expert knowledge for different uses. Rummens (2012) highlights three models of knowledge transfer between academics and policy decision-makers. There’s the push model in which producers of knowledge push scientific research findings out to decision-makers. The pull model is based on demand for research findings. Lastly, knowledge transfer and exchange mechanisms which are rooted in sustained interaction of both producers and users. The ability to demonstrate an ongoing presence in policy or practice systems is fundamental to taking advantage of opportunities to influence policy and/or practice (Mandeville, 2007). The ongoing interaction and dialogue between knowledge producers and consumers enhances the planning, production, dissemination and application of research within decision-making (Rummens, 2012).

Rummens (2012) attributes greater knowledge uptake and receptivity of policymakers to research findings when they are involved in the entire research process, from identification and prioritization of research agendas. Landry et al. (2003) found that that successful knowledge utilization by policy-makers, depends on users’ acquisition efforts, scholars' adaptation of research products, the intensity of links between scholars and users and on users’ organization contextual factors. Cohn (2006), Shields (2007) and Rummens (2012) argue that a ‘third community’ of actors, usually government workers, bridge the space between decision-makers in government and academics. The 'third community’ supports the efforts of decision makers. Meyer (2010) and Rummens (2012) refer to these people as knowledge brokers within government bureaucracies, whose job 
it is to move around and create connections between researchers and their various audiences.

Knowledge utilization faces several practical challenges. Government departments are operationally structured and focused, therefore lack resources to stay connected to a vast quantity of research outputs (Clippingdale, 2006). Information overload is a common complaint by policy decision makers, especially in light of advances to communication and technology (Clippingdale, 2006; Shields \& Evans, 2008). Governments are addressing complex problems that require increased coordination for resolution (Shields \& Evans, 2008). Another explanation is that policymakers are unable to make effective use of academic research (Guston et al., 1997 as cited by Boswell, 2007). Rummens (2012) states, a major challenge of linking research to policy is that academe tends to favour and reward the advancement of scholarly knowledge, offering few incentives for university-based researchers to undertake policy and practice relevant research. Shields \& Evans (2008) find that traditional sources of academic dissemination of research findings, have not been effective or directed at audiences beyond the scholarly community. Standard academic written dissemination outlets are peer reviewed academic journals and books with long publishing timelines, written primarily for very narrow audiences or peers almost always in highly discipline specific language.

\subsubsection{Knowledge Mobilization in Canada}

SSHRC, Canada's leader of academic funding for social science research has embraced community engagement in its mandate. CERIS's commitment to community involvement in all aspects of research projects and the institution itself, ensured a strong 
connection and influence of community partners on academic research and vice versa. Community-based research provides a source of the 'lived' experience of restructuring and policy changes on the ground, through detailed and empirical evidence (Shields \& Richmond, 2004). They found there was a lack of research and a significant knowledge gap concerning the nonprofit sector as a whole, contributing to an inability to comprehend the needs and stresses faced by settlement services and their users. This is a gap, which Metropolis among other initiatives, have aspired to fill.

CERIS has been credited as the prototype for SSHRC's Community-University Research Alliances (CURA). The CURA grants support the creation of alliances between community organizations and postsecondary institutions which, through a process of ongoing collaboration and mutual learning, foster innovative research, training and the creation of new knowledge in areas of importance for the social, cultural or economic development of Canadian communities (SSHRC, 2010). At the $9^{\text {th }}$ Annual Metropolis Conference, President of SSHRC, Dr. Gaffield made the connection between CURA and Metropolis stating, “CURA’s complement joint initiatives, illustrated by the partnership that supports Metropolis.”

The current strategic plan for SSHRC (2010-2012) seeks to enable connections, among researchers, across disciplines, and between the university and the larger society. This addresses the changing world of research in which specialization is being combined with contextualization, as strategies for advancing knowledge and building understanding. Alike CERIS, SSHRC has also moved to a governance structure, composed of both academic leaders and those from the larger society, deepening the 
engagement of Canadians in the research activities of the social sciences and humanities (SSHRC, 2010).

Another objective from SSHRC Strategic Plan (2010-2012) is concerning the impact and value of research to make a difference in the lives of Canadians. They acknowledge the difficulty in evaluating this, as well as their ongoing pursuit of mobilizing knowledge to increase potential impact. This is also found in an internal CIC review of the Metropolis Project, criticizing Metropolis’ inability to provide specific identifiable policy results and calling for more innovative and persistent approaches to demonstrate benefits of Metropolis-stimulated research to senior policy makers and politicians (Clippingdale, 2006).

SSHRC trends show an increasing emphasis on knowledge mobilization, enabling research to have mechanisms to contribute to policy decisions. Their knowledge mobilization strategy (2009-2011) seeks to: 1) enhance flow of research, facilitate relationships between researchers and users; and 2) develop networks, tools and best practices. These trends are grounded in the same values that made CERIS a unique and innovative partnership. There is increasing expectation that while not to the same degree as CERIS, researchers must undertake collaborative approaches and embrace knowledge mobilization strategies when applying for research funding (Interview \#5, June 17, 2012). The increased attention to community involvement and shared governance at SSHRC integrates the same values that made CERIS a forward thinking initiative. CERIS is now functioning in an environment where in some ways, the status quo for social science research and expectations laid out in funding agreements today, is part of what made CERIS so beneficial for all parties and the wider society when it was first established. 


\subsubsection{Non-Profit Funding Context for Research}

Research and advocacy is an important function of nonprofit organizations, including academic institutions involved with informing policy development in Canada. The environment for research and knowledge production is quite robust. Organizations generate research about immigration policies and their effects from various perspectives including; think tanks, private research firms, community-based researchers and through government procurement (Kyeung, 2012). Research centres such as the recently established Ryerson Centre for Immigration and Settlement, the newly transitioned National Metropolis Centre at Carleton University and the long established York Univeristy Centre for Refugee Studies are continuing to produce research in the field of immigration. At the same time, individual faculty build on existing knowledge, respond to policies, partner with community-based organizations and governments and continue to generate research grants and produce expert knowledge in this field.

Although CERIS is not a typical community-based organization, it is vulnerable to the political and economic funding environment of "the third sector". The third sector refers to organizations situated in between public and private sectors. The agenda of the Conservative Government is felt in funding allocations across the sector, including organizations working in the field of immigration and settlement. Common trends within government as a whole are deficit reduction or elimination, managing reduced program spending, market approaches to resource allocation and outsourcing service delivery (Clark, 2002). Funding cuts, discontinued programs and shifting models of service are reflected in the current political orientation (Banting, 2010). This includes the transformation from “core” to "program” funding (Shields \& Richmond, 2004). It is also 
evident in government's push to link academic research in natural sciences and engineering to the private sector through industry driven collaborative research and development programs (NSERC, 2012).

Shields and Evans (2008) note that in the case of CERIS core funding was greatly coveted by university administrations, and was fundamental to its establishment. In 200506, SSHRC launched a pilot initiative, to support partnerships among researchers and receptor communities from industry, government and not-profit organizations (not dissimilar to the Centres of Excellence and the Metropolis Project). A 2009 evaluation of that pilot project found that sustainability of these partnerships relies on the capacity of the networks to secure funding for their infrastructure and operational funding. It found that while some networks were successful in obtaining financial contributions from partners to support specific networking activities, knowledge transfer initiatives, and research activities, they tended not to be very successful in obtaining a sustainable level of operational funding (Bertrand et al., 2009). 


\section{Theoretical Perspective and Literature Review}

\subsection{Theoretical Perspective}

This case study assumes a constructivist perspective, which values multiple individual perspectives and tacit knowledge to enhance the understanding of organizational capacity within one organization (Stake, 1978; Guba \& Lincoln, 2003; Misener \& Doherty 2009). Adler (1997) states that the modern constructivist approach acknowledges that the social world is made of intersubjective understandings, subjective knowledge, and material objects (as cited by Lupovici, 2009). The knowledge will be developed through the interpretations and experiences of the research participants and in conjunction with theories found within the literature on nonprofit organizational capacity.

\subsection{Literature Review}

\subsubsection{Organizational Capacity in Non-profit Organizations}

Organizational capacity is likened to a critical toolkit that enables small nonprofits to operate effectively under uncertain and dynamic circumstances (Kupucu, 2008). Various definitions and frameworks have emerged to describe organizational capacity, yet because of the variety of nonprofit organizations, and their unique characteristics, there does not exist a one-size fits all framework. This can pose many difficulties in determining how best to conceptualize what an organization's capacity is. Given this inconsistency and the unique features of CERIS, this section presents peer reviewed articles that have explored capacity in a variety of different ways. 
There are three sections that make up the literature review for the case study followed by the development of a theoretical framework used to answer the research question. Initially, I look for consistencies in the literature about how the concept is used and what it refers to. I then narrow the focus on the core competencies of organizations and the two areas that I have deemed most relevant in this study, human resource capacity and resource acquisition capacity. Lastly, I discuss of the organizational context, which in this case is academic partnerships.

\subsubsection{Understanding Capacity in Nonprofit Organizations}

Despite its variations, organizational capacity is broadly defined as a set of attributes that help or enable an organization to fulfill its mission and objectives and sustain itself over the long term (Chaskin, 2001; Eisenger, 2002; Newborn, 2008). Organizational capacity frameworks vary in the number of and names of dimensions, however, there are many common features such as human resources, financial (or capital) resources, degrees of formalization and external linkeages (Misener \& Doherty, 2009; Hall et al., 2003). In the nonprofit literature, Hall et al. (2003), understand organizational capacity through an analysis of such domains as human and financial resources, relationships and networks, infrastructure and process and planning development capacities and how they work together. Glickman and Servon (1998) argue overall capacity consists of resource, organizational, networking, programmatic, and political components. The majority of definitions share a commonality, in that they view organizational capacity as a concept made up of various interdependent parts.

Research stresses the importance of how capacity functions and how it is managed, which relates to a governance structure. Effective organizations tend to have a 
broad array of capacity attributes and use or mobilize that capacity to fulfill their organizational missions (Eisenger, 2002). Hall et al. (2003) argue, that for a nonprofit and voluntary organization to produce the outputs and outcomes it desires, it is a function of its ability to draw on or deploy a variety of types of organizational capital. Barman and MacIdoe (2012) discuss capacity as the actual internal ability of organizations to enact a specific task and draw on the presence of written rules governing action and organizational members with specialized knowledge. Chaskin (2001) focuses on the ability of organizations to carry out their functions responsively, effectively, and efficiently as part of the larger system of actors and processes to which they are connected. Sowa et al. (2004) capture the nature of capacity perhaps most holistically, by referring to how the organization or program operates, the structures in place (internal and external), and the operating processes that dictate and direct peoples' action.

Various researchers emphasize different priorities in assessing organizational capacity. Hall et al. (2003) for instance, identify human resource capacity as the most critical factor for organizational goal achievement. Glickman and Servon (1998) identify effective partnerships as particularly important for capacity building initiatives to improve planning and financial management through connecting with needed resources and support. Chaskin (2001) found that engaged individuals and the strengthening of associational networks were critical to success. He reconciled the diversity of foci of capacity by highlighting consistencies found within the literature which are: 1) the existence of resources (ranging from the skills of individuals to the strength of organizations to access financial capital); 2) networks of relationships; 3) leadership 
(often only vaguely defined); and 4) support for some kind of mechanisms for or processes of participation in collective action and problem solving.

Misener and Doherty (2009) highlight that capacity is multidimensional. This view suggests that one dimension inhibits or mobilizes other forms of capacity. Glickman and Servon (1998) argue that it is easier to identify what kinds of capacity exist in nonprofit organizations in theory than to measure them in practice. Wing (2003) recognizes that one of the challenges in the implementation of nonprofit capacity building, relates to the fact that the concept of capacity is referenced at a very high level of abstraction.

Sowa et al. (2004) assert that a multidimensional model represents a promising way to capture nonprofit organizational effectiveness, but the dimensions will vary based on the uniqueness of organizations. To account for this, the nature and impact of each dimension should be considered individually and connections among them discussed, while accounting for differences in organizational context (Misener \& Doherty, 2009). Since capacity measures are not the same across all organizations, organizational context plays a crucial role in understanding an organization's capacity (Cuskelly, 2006).

External factors are of critical importance and can either enhance or disable an organization to achieve its goals. The ability to develop or maintain capital depends on external factors such as environmental constraints and facilitators, access to resources and historical background. Eisinger (2002) specifies that the economy, the legal and regulatory framework, and the availability of human and financial resources affects organizational capital accumulation. Growth and survival of an organization are linked to the consistency of or changes in the environment (Salimath \& Jones III, 2008). As 
Meinhard et al. (2011) explain, the relationship between organizations' and their environment can rarely be described through linear and rational assumptions. Instead, the process of self-organization often occurs, when a complex system of partnerships is constantly adapting to the contingencies of the day while the system transforms itself.

Research on transformation and change points to several different factors that enable or disable organizations to successfully adapt. Tushman and Romanelli (1994) and Kotter (2005) as cited by Meinhard (2008) found that timing was the strongest predictor of successful change. Managing change in nonprofit organizations requires attention paid to leadership, stakeholder management, planning, team selection, communication, decision-making and cultural awareness (Crawford \& Nahamia, 2010). Sowa et al. (2004) argue that organizational capacity to adapt is directly linked to individuals' capacity to adapt. So, a culture of collaboration and trust are essential elements to support individual learning in an organizational environment. Nutt (1998) finds that organizations can transform with inspirational vision and leadership, whereas failures to do so are more apt to stem from a scarcity of opportunity than from a scarcity of capital.

\subsubsection{Core Competencies: Financial \& Human Resources}

To understand an organization's capacity to meet environmental demands, issues to consider include: the range of products and services provided by the organization; the distribution network for its products; the geographic distribution of its activities; how existing structures perform; human resource systems; and its financial positioning (Hatch, 1997). These areas refer to the core competencies of organizations.

According to Hall et al. (2003) human capital is considered to be the key element that leads to the development of all other dimensions of organizational capacity. For 
example, the creation and maintenance of financial capital requires human capital with competencies in fundraising and finance. Planning and development capital requires competencies in leadership and strategic management. This viewpoint coincides with a resource-based view of organizational strategy and the vast literature on human resource management (Clardy, 2008). According to this view, core competencies in human resources leads to superior performance of one firm in comparison to its competitors. Mesch (2010) finds that the human element is the most fundamental factor in organizational performance across public, private and nonprofit sectors. Further, attracting, motivating and managing human resources is the most significant source of competitive advantage. Of particular importance is that core competencies are the mechanisms that not only yield superior performance but also become an engine of organizational renewal and innovation (Cuskelly, 2006).

There is vast literature on the integral nature of human resource capacity. Glickman and Servon (1998) refer to the internal operations of an organization as critical components-how it manages itself, employs staff, develops its human capital, relates to its board of directors, and manages its finances. Human resource capacity is the ability for an organization to deploy human capital (i.e., paid staff and volunteers) within the organization, in other words, to used to best advantage the competencies, knowledge, attitudes, motivation, and behaviours of its people (Misener \& Doherty, 2009). Strong boards, effective managerial leadership, and the assessment of organizational performance are crucial to the successful operation of a nonprofit organization. Staff development, recruitment, and systems of incentives for employees strengthen an organization’s human resource capacity (Mandeville, 2007) 
Although human resources were identified as one of the greatest strengths of nonprofit and voluntary organizations, Hall et al., (2003) identified a number of challenges in this area. The most frequently identified human resources capacity issue was the need for more volunteers. Volunteers are increasingly unwilling to take on leadership or administrative roles or to make long-term commitments. The second most frequently identified human resources capacity issue was the need for more paid staff and, in particular, for more staff with specialized skills (e.g., managers, fundraisers, accountants, information technology specialists). Lastly, targeted recruitment strategies in order to develop boards with the right mix of people and skills, and the need for organizations to clearly define the role of their boards were defined as human resource capacity issues in nonprofits (Hall et al., 2003). Mesch (2009) points out that boards need to play more of a role in fund development and work with staff to access key resources by engaging and cultivating key relationships, soliciting gifts, and providing stewardship to donors. Additional human resource issues include difficulties in retaining staff to help with revenue generation over the long term and recruiting and retaining staff, board members, and volunteers with fundraising skills (Hall et al., 2003).

Hall et al., (2003) found, one of the most pressing challenges reported by nonprofits is related to financial capacity, and the ability of firms to increase, manage, and sustain funding of their operations. Among the critical issues are: 1) funding expectations and requirement of external funders, notably government; 2) the need for more funding; and 3) changing priorities of funders and the diversification of sources. Funding is rarely provided to promote the ability of organizations that influence policy to develop resource acquisition capacity and management and governance capacity 
(Mandeville, 2007). Bertrand et al.’s (2009) evaluation of Network Centres of Excellence (NCE) found that the sustainability of developed partnerships relies on the capacity of networks to secure funding for their infrastructure and operational funding, which at the time of their study was uncertain, as this had not been attained. Mesch (2010) calls for an emphasis on entrepreneurial ventures and social marketing; less reliance on public money and renewed collaboration between private, public and nonprofit institutions.

\subsubsection{Research Partnerships}

Organizational context, including the specific details of the organization and the environment that it is functioning in, play a critical role in understanding its capacity and ability to transform. Limited studies have shown how partnerships with academia can be used to enhance knowledge use and achieve social change (Mandeville, 2007; Shields, 2007; Anisef et al., 2007; Shields \& Evans, 2008; Gatta \& McCabe, 2008; Boswell; 2009; Rummens, 2012). Universities have realized that they must form and maintain new external relationships between university staff and outside bodies (be they government, corporate, or community leaders). Successful partnerships are seen to move forward policy agendas that address issues of social justice (Gatta \& McCabe, 2008).

Partnerships intended to influence policy often include the implementation of a program or project based on a formal agreement to achieve a common purpose (Erskine, 2002 as cited by Shields, 2007). Mandeville (2007) and Hall et al. (2003) contend that for partnerships to be successful, attention must be paid to the organization's capacity to achieve a level of self-sufficiency and self-direction. Hall et al. (2003) maintain that the need to stay independent and maintain community-based agendas is an integral part of the work being done by nonprofits. Despite this, it is more important for organizations to 
build and sustain relationships to adapt to new and difficult environments than the need for independence. Piccolli \& Wagner (2003) argue that for a partnership to work with practitioners, academics must understand the practitioners' issues and challenges and practitioners must take time to help set research agendas and strengthen relationships. Successful partnerships require recognition and understanding of the challenges of the partner organizations. At one point in CERIS's history, this took the form of meetings between Vice Presidents of Research of the partner universities, an uncommon occurrence (Interview \#6, June 13, 2012.)

Sustainable projects remain an ellusive, yet ideal goal for many nonprofit organizations and initiatives. Clearly, for research collaboration and partnerships to achieve success, the needs and priorities of its funders must be taken into account, even while maintaining a level of independence to develop unbiased, diverse research agendas. Boyer (2008) describes four straightforward components of a successful academicgovernment model; common vocabulary, mutually agreed upon timelines, jointly prepared outcome measures and an agreed upon dissemination model.

\subsection{Theoretical Framework}

Existing frameworks for studying the organizational capacity of academic research centres, especially such with the uniqueness of CERIS are limited. In one study, Mandeville (2007) did however look at the role of private foundations in funding the capacity of organization's mandated to influence policy (policy actors). Similar to Metropolis, a key activity by policy actors is the provision of information and knowledge exchange to policymakers. The research suggested ways of investing in the stability and effectiveness of policy actors over the long term. 
The attributes that any particular organization possesses constitute the organization’s capacity profile (Eisinger, 2002). Mandeville (2007) suggests that policy actors have three types of organizational capacity: 1) research and communication capacity; 2) resource acquisition capacity; and 3) management and governance capacity. From what is known about the multidimensionality of capacity, all three areas are necessary and critical a policy actor’s organizational capacity in relation to its environment.

Mandeville (2007) finds effective management is a necessary prerequisite for the development of research and communication and resource acquisition capacity. An organization that is administered and governed capably is more likely to be effective in achieving its goals. The possession of appropriate management capacity, having systems in place, certain structures and processes that support the operations of the organization, is a critical indicator of the effectiveness of an organization and is represented in the framework (Sowa, 2004). The framework that will be used to understand CERIS’s organizational capacity is reflective of human resource capacity and financial capacity frameworks and the three capacities articulated for policy actors. They have been adapted to the partnership model and the specific context. From this theoretical framework and literature review, the following framework is being used to assess the organizational capacity of CERIS. 


\subsubsection{Figure 1: Framework for Assessing Organizational Capacity of Policy Actors}

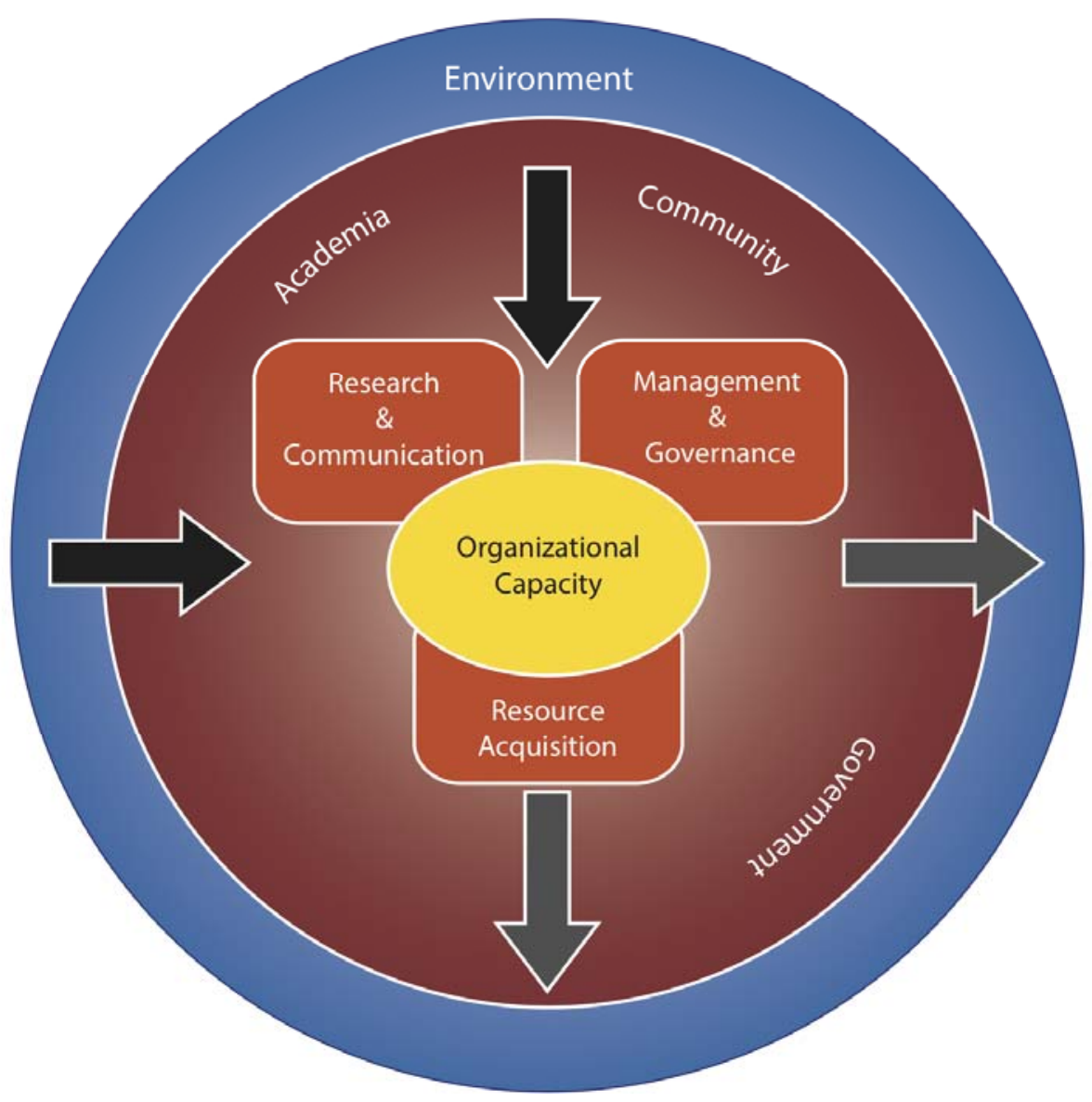

\section{Research Methods}

\subsection{Research Approach and Strategy}

The case study uses a qualitative approach because of its interpretive and crosscutting nature. Qualitative research is surrounded by “a complex, interconnected family of terms, concepts, and assumptions... [that] include the traditions association with foundationalism, postitivism...postpositivism, poststructuralism, and the many qualitative research perspectives and/or methods, connected to culture and interpretive 
studies” (Denzin and Lincoln; 2003; p3 as cited by Williamson, 2006). In other words, the research approach is embedded within a host of other perspectives that shape individuals' interpretations of the social world. The goal of the research is to expand on CERIS's organizational capacity to sustain itself in the future based on the data and findings that emerge. The research emphasizes an inductive style of reasoning, such that meanings from the data can be inferred to further understanding about CERIS. Sowa et al., (2004) state, both objective and perceptual measures enable scholars to better capture the actual construct of organizational effectiveness and in this case, organizational capacity, being studied. It is important therefore that the research permit a contextual understanding of the phenomena under study, to wit the capacity of CERIS from the perspective of the research participants (Archer \& Berdahl, 2011).

Case studies contribute uniquely to our knowledge of individual and organizational processes and provide opportunities to deal with a variety of evidence types, including documents, artifacts, interviews and observations, all of which have been used to conceptualize CERIS’s organizational capacity (Yin, 1989).

\subsubsection{Selection of Participants}

I chose 6-8 key informants according to the following criteria: time of involvement, roles undertaken and institutional affiliation. I selected participants from each academic partner institution, a community partner and an external stakeholder such as a government affiliate. I recruited at least one representative from the following roles; a current or former board member; a domain leader; a director; a staff person and an outside stakeholder. The spectrum of perspectives was intended to give a holistic picture of the organization and add depth of analysis. 
The participants were recruited using personal contacts, information available on the CERIS website and lists provided by the CERIS administrator. The CERIS Board of Directors granted permission to conduct the research. The research methods were approved by the Ryerson Ethics Board.

Because informants in this study come from a limited pool of individuals, participation in the study was confidential, and specific attention was given to omitting any details that could provide identification of respondents or others within the organization. Much of the results are summarized and presented in aggregate form to protect confidentiality.

\subsubsection{Data Collection}

As a former intern for CERIS, I was able to generate a broad collection of data. The provided opportunities, such as access to organizational information in the form of stakeholders and documents, which would otherwise be limited. I also gained a more nuanced understanding of the case and issues prevalent to CERIS through my own experience with the organization.

The data included memorandums, written evaluations, reports, presentations and meeting minutes, as well as organizational records, survey data and lists. The documents and records provided details and background about organizational structure and processes and objectives. The main uses of these documents were to provide information about the organizational structures and processes, and augment the data obtained from the interviews.

The primary data collection tool that I used for the study was the semi-structured interview. Key informant interviews are conducted with individuals to access specialized 
information (Archer \& Berdal, 2011). Semi-structured and focused interviews (about one hour in length) allowed for respondents, in a conversational manner to explore the set of predesigned questions and topics developed to assess organizational capacity (see attached appendix for interview questions). The respondents were in the ideal position to provide data because of their experiences with CERIS and their professional experiences and opinions regarding research. I was interested in whether the participant thought CERIS had the capacity to continue without Metropolis funds. It was important for my understanding to explore why professionals have been involved with CERIS and motivating factors for sustained involvement or potential involvement in the future. The interviews with current, invested stakeholders and previously invested stakeholders provided a bases for evaluating CERIS’s organizational capacity.

The interviews were recorded and transcribed verbatim. Data was organized and identified by the most relevant area of capacity.

\subsubsection{Scope and Limitations}

This Major Research Paper has an applied focus and attempts to describe the organizational capacity of a single organization. A critical limitation of this study about the future of CERIS based on a single theoretical framework - organizational capacity, past occurrences and the personal views of the participants. The interviewees are not representative of all those currently involved with the organization, nor, do they make decisions regarding the funding allocations of partners. Another set of participants may have different and/or to some extent more current knowledge about CERIS capacity based on their current roles. The organizational capacity is based on a theoretical construct and may or may not be applicable in the applied setting. As a single case study 
of an organization, the findings are most applicable to the unique context of CERIS, while the specific methods and framework could be applied to other organizations in similar situations.

Other limitations of this study are due to time constraints. The time given for completion of the research is between June and August 2012. More time would have allowed for more interviews which may have strengthened the analysis. The research is being developed and implemented by a Masters student, under the guidance of a faculty supervisor at Ryerson University. 


\section{Findings and Discussions}

Before discussing the key research questions, it is important to note that the interviews revealed a range of opinions with respect to the ability of CERIS to continue operation. There were wide differences of opinions as to: 1) the possible sustainability of CERIS and its partnership model; 2) how the institution might generate funds; 3) the form and function that a renewed organization might take, if any; and 4) the value that a future CERIS might have.

There was unanimous agreement, however, that the changing demographics and prevalence of newcomers in Ontario and specifically the GTA provides a suitable backdrop for the continuation of an organization like CERIS. Most likely, this would be as an initiative committed to capacity building and increasing cross-sectoral understanding of the experiences and consequences of immigration and immigration policies, in a specific geographic location.

There are all kinds of reasons why people would want to be involved with CERIS. It's located in Canada's largest city, with the highest percentage of not only foreign-born people but visible minorities. There are a lot of people in Toronto who are interested in this issue and I don't see that changing anytime soon. (Interviewee \#2)

Given the impending changes to funding and consequently the infrastructure of CERIS, there was general agreement that stakeholders need to reassess CERIS's priorities and make critical decisions moving forward. This is supported by recent organizational efforts such as the establishment of a future planning committee, a survey to stakeholders and a Townhall Meeting. 
"What is the value of what we are doing and how do we support the continuity? Is it doable. Absolutely. It's a natural development...this is exactly what should be happening, but what are the decisions now, and where is the support coming from. Who is going to dance together?” (Interviewee \#5)

There's nothing wrong with saying you have accomplished many of your goals and its time to reassess your priorities. (Interviewee, \#7)

Generally respondents felt the disbanding of CERIS will leave a void in the GTA for an institution that can convene stakeholders and act as a gathering place for its community. CERIS is different from other research centres, in its ability to serve that unique networking function of convening different of parts of society to learn and understand immigration and settlement from multiple perspectives. All of the respondents felt that the network provided various benefits to the range of stakeholders.

Having a place to go, having a community of researchers that is engaged with civil society can, although it is a lot less formal now, but who is able to engage with government is going to be attractive. People like to be convened and CERIS was very good at convening people. There is certainly going to be a continuing demand for people to be involved with an organization like CERIS (Interviewee \#3).

Many of the networking functions provided by CERIS were extremely valuable and will be missed, unless they are realized in alternative forms (Interviewee \#7).

A point of dissensus concerned whether or not an institution was necessary to continue similar knowledge mobilization activities. Sustaining knowledge mobilization requires ongoing interaction between knowledge producers and knowledge consumers, but not necessarily a physical infrastructure. The majority of participants suggested that individuals, research teams and research centres would undertake some of the same activities without the funding and infrastructure provided by CERIS. Several participants felt that the mandate had successfully been accomplished and the institution would 
discontinue in its current form. Others felt that the organization had the potential to reformulate and continue to serve a function with regard to immigration and settlement research and the community of knowledge producers and users.

The following section describes CERIS through the three capacities associated with policy actor organizations: resource acquisition; research and communication; and management and governance. It presents opportunities, challenges and conditions for a renewed CERIS-like institution.

\subsection{Resource Acquisition Capacity}

The capacity for human and financial resource acquisition is critical to developing a sustainable network. The data shows that the most critical challenge facing a renewed CERIS-like institution to acquire resources as a multi-stakeholder partnership, is the removal of incentives to collaborate. For a CERIS-like institution to acquire resources for continued knowledge mobilization, the following interrelated practicalities are necessary: the acquisition of core funding, institutional incentives to collaborate, and community organizing/a bottom-up approach along with sustained participation.

\subsubsection{The Challenge of Core/Institutional Funding}

Generally, respondents acknowledged CERIS faces challenges with regards to generating institutional funds. There appears to be a greater likelihood of receiving government funding for collaborative research projects, knowledge mobilization activities, and research that builds in successful knowledge mobilization practices than for core funding for organizational infrastructures. It was noted in several instances however, that CERIS was able to generate extremely high value for relatively low investment. The funding of CERIS operations was moderate in relation to large research projects. The institutional 
needs are not excessive and can be generated through both financial and non financial contributions. Many respondents felt that a partner could provide office space and some administrative assistance, and that this would ideally be an academic partner (i.e. a university).

"The reality is, the funding levels were never very high. I have research projects that are double, easily and those aren't the biggest research projects that I have. So, put it into perspective in terms of what is really needed.” (Interviewee \#5)

Several suggestions were made as to how a CERIS-like institution could acquire financial and non-financial resources to sustain an infrastructure. For instance, it could be done by tapping into project funds and embracing entrepreneurial approaches.

\subsubsection{Tapping into Project Funds}

The prevailing nonprofit funding environment, especially from governments, favours project funding over institutional or core funding. It is more likely that there are opportunities for CERIS stakeholders to raise funds for specific collaborative research projects and/or knowledge mobilization activities. CERIS (or one of its academic stakeholders) could take the lead on a partnership grant or a CURA, or other project grants such as SSHRC’s Connection Grant. The latter supports events and outreach activities geared toward short-term, targeted knowledge mobilization initiatives. These projects could provide a revenue source for some of CERIS's operational needs by including specific expenses within budget lines and/or building in additional funding to cover costs such as website upkeep and a staff salary. The existing CERIS infrastructure and relationships can be used to add competitive advantage to grant applications. The opportunity to generate revenue from hosting a conference was also suggested (Interviewee \#1). 
“...people who apply for grants using CERIS name would have to build in an component to keep the organization running, you know 10, 15, 20\% of the grant, would have to go into administrative overhead...” (Interviewee \#3)

\subsubsection{An Entrepreneurial Focus}

For continued activities in the competitive funding environment, it is increasingly important that CERIS and its stakeholders employ entrepreneurial strategies to acquire funds. Participants described a couple of tactics for this. Individual researchers and collaborative teams can compete for general research grants with private research firms. They can use cost-efficient resources such as graduate assistants and university reputations to give them competitive advantage over research firms in procuring contracts. Further, they can leverage partner resources and tout their enhanced ability to mobilize knowledge for practical or policy related purposes.

Another opportunity highlighted was to charge a fee for individual and institutional affiliation. As an institution, it was acknowledged that CERIS has generated an excellent reputation both nationally and internationally. Its reputation has been enhanced by its various achievements over the years, its ability to increase the value of public funds, its careful management of government funding and its ability to leverage resources. Further, it both has credibility with its various partners and adds credibility to partnered institutions and affiliates. The credibility that CERIS has with civil society and government facilitates stakeholder involvement, as CERIS's acts as a convenor for immigrants, organizations serving immigrants, academics and officials in one place. The benefits that were discussed in describing the institutional context show that there is value for individuals and institutions to be involved in the network. As such, a couple of participants acknowledge that if CERIS can continue to add value for affiliation, membership fees could sustain some infrastructure funds. 


\subsubsection{Incentives for Collaboration}

A critical finding stated by the majority of respondents was that incentives to collaborate were fundamental to the partnership. Moving forward, they acknowledged, partners need tangible benefits to work together. The appeal for academic institutions to work together was weakened when the incentive of government funding was removed.

"...there is no money anymore. And there is no pressure from Ottawa anymore...there is no reason to collaborate, people have other things to do, and their research departments will be rewarded for getting money that (the other institution) didn't..." (Interviewee \#7)

To unlock resources, CERIS needs to identify potential partners whose goals are to make lives better for newcomer Canadians. This changes the focus from federal partners to potential partners at different levels of society. A couple of respondents strongly felt that there are real benefits for a range of stakeholders, especially at the community level, to be realized from involvement in an organization that focuses on knowledge mobilization. The organization therefore could identify and engage new partners at different levels, although this will have implications on the types of knowledge mobilization activities. A representative of a community partner indicated that their organization would remain committed to working with a renewed CERIS in whatever form it took.

"Where's the information, knowledge and the need that relates to current issues?” (Interviewee \#5)

“...increasingly in those [local] agencies there are newcomers who have PhD's and research experience and so...on the ground service providers are now through their staff acquiring the capacity to be more involved in research."(Interviewee \#6)

"...recognizing the issues and the needs, the resources and the responsibilities that really have an impact on the lives of our newcomers are also at the 
provincial level and the municipal level...[for example issues such as] health and education...” (Interviewee \#5)

\subsubsection{Community Organizing/Bottom-up Approach and Sustained Participation}

A renewed CERIS necessitates an emergence from the bottom up, through individuals' efforts to foster commitment from partner institutions. Without government funding, stakeholders will have to make the case that it is worthwhile for institutions to invest resources into the partnership. For renewal efforts, sustained participation of motivated individuals is necessary to draw in the universities and other institutions, however there are various constraints to this.

Data shows that the renewal of the organization is dependant on the individual efforts of stakeholders, presumably faculty, and their investment of time and energy beyond any mandated responsibilities. These are essentially volunteer contributions. According to most stakeholders, this type of effort was necessary to sustain the current organization and is certainly necessary to renew the organization during this period of uncertainty.

"A lot of the success of CERIS can be attributed to the dedication of a few core people. A lot of it was volunteer time. A lot of it was time over and above the time that was part of a job. Because everybody had a core job at an institution so CERIS came often on top of that." (Interviewee \#5)

"It would take a significant amount of time raising money, raising interests, convincing universities to do what they need to do. It would be an enormous undertaking.” (Interviewee \#3)

There are several obstacles impeding this level of participation. There is less motivation and fewer incentives for academics to remain involved, in particular, with respect to research funds, publication opportunities and engagement of Federal 
government partners. There are fewer career development opportunities and in some cases participation could hinder academic career advancement. Further, the collaborative nature of the organization means that despite its discontinuation, stakeholders (excluding the administrative staff) still have their own institutions, committments and work responsibilities to attend to. Remaining involved is not critical to their livelihoods.

“...whether you're an academic, civil servant, or an executive director of a settlement organization, you need to manage your career first..." (Interviewee \#7)

The findings further suggest that the people who will continue to be involved with the renewal efforts of CERIS are academics and community-based stakeholders who are driven by its purpose; designing and implementing research for political and practical utilization. It was further noted that the age demographic might play a role in sustaining involvement in the reorganization. Faculty members with less pressure for traditional academic career advancement have less job-related disincentives to actively participate.

“...the goal wasn't just to do research, it was to do research for a reason, and there's a very clear sense of what the purpose was, and what the hopeful outcomes were...” (Interviewee \#5)

“...established academics would still be involved because they believe in it. People are driven by there own values and beliefs" (Interviewee \#7).

“...research that is done that addresses key issues, social issues, that is geared towards helping to inform policy...It's not for everybody, not everyone wants to do it..." (Interviewee \#5)

"we need people who say 'this is important to me' but the thing is, you see what brought people to the table last time was the funding opportunity."

(Interviewee \#6) 


\subsection{Research and Communication Capacity}

There was general agreement from the research participants that CERIS has been very successful in producing policy and practice relevant research on immigration and settlement issues. A small group of participants acknowledged that CERIS research could add value to federal, provincial and municipal governments in their ongoing, complex and highly contested jurisdictional relationship around immigration and settlement issues. They felt that the provincial government and municipal government would be the most likely new partners and consumers of knowledge, while acknowledging the difficulty in generating funding at the municipal level.

“...in terms of funding, there are needs that are provincial and needs that are municipal. We have colleagues there as well, and there is need for the information." (Interviewee \#5)

To optimize its research capacity, most participants maintained that there should be involvement from at least one partner university and the involvement of academic researchers, because of the value of academic knowledge. Differentiation was made between the research produced at universities than that of the NGO sector and government partners. Academic institutions also have the financial capacity to pay for faculty. The value that about half participants found however was not as a traditional research centre or a think tank. They felt this does not add enough value to partners, as current affiliates will continue to generate research funds and produce new knowledge on immigration.

"[Its greatest chance for success] ...would be something that aimed to convene and that's why I say the SSHRC partnership grants, and there are other grants that SHHRC gives that are designed to build intersectoral connections...I think this is something CERIS could probably succeed in getting money because they have such credibility in this sort of thing already." (Interviewee \#3) 
"Research that academics do has more data and value...it holds more weight [than other types of research], the words have more authority and that can be useful." (Interviewee \#6)

Engaging new partners means furthering CERIS’s research and communication capacity. For instance the connections through the network are diverse, and different knowledge producers and knowledge consumers require different types of knowledge exchanges. This includes academics to other academics, academics to government, community groups to academics and government and vice versa and whatever new partnerships emerge. Respondents felt that with the hiring of knowledge mobilization officer CERIS was applying new technological capabilities towards advancing the network. However, a couple of participants acknowledged that CERIS has not always been able to engage a range of partners, such as the smaller community based organizations, beyond its institutionalized stakeholders. As was noted:

"What we learned was that our ability to relate to organizations really has to vary, because the capacity of organizations to engage with CERIS varies. So OCASI, Social Planing, Access Alliance, the United Way even Woodgreen have a research capacity, and they're more able to engage with us. The small service providers have less capacity to both help us with the research, and even to consume the research; or to inform how a research project should be designed." (Interviewee \#6)

“...having a dialogue with NGO representatives who don't do research but are very concerned about the policy and the program issues is a different kind of discussion, and it might need to be structured differently. And I'm not sure, particularly in the later years that CERIS was keeping up with the evolution." (Interviewee \#7)

In terms of renewal efforts, participants revealed that increased communication about the transition efforts was necessary to sustain interest and a continued connection to the organization and a potential new form. It was observed that: 
“...what I know, and others will know from going through organizational change is that communication about what is happening and what the direction is...input into planning, that's welcome, there's a need for communicating about the change and the possibilities, otherwise people wonder. You know. And when people wonder they are not able to be part of moving towards..." (Interviewee \#5)

\subsection{Management and Governance Capacity}

The data and available literature reveal that CERIS's governance policies and structure have both positive and negative implications for future organizational capacity. While many respondents called for a leaner governance structure, others found that multiple opportunities to participate in the governance and/or management of CERIS could keep individuals and institutions engaged. As noted

“ a [governance] model that has a managing director and representation from the three universities, sort of almost a small steering committee, with maybe a representative from one of the community organizations, sort of like what exists now at the management level, but not sort of what exists now [at the larger governance board level]. (Interviewee \#1)

"...this elaborate structure served them very well in other ways. For example, the various committees they had in place in addition to the management board, they all involved different partners, different characters of society, government, the civil NGO sector and this bought them I believe a lot of credibility...people knew they were going to be included." (Interviewee \#3)

The multiple opportunities for individuals' involvement on different committees or councils seem to have contributed to their prolonged involvement over time. Every participant interviewed had taken on more than one role. Further, individuals and organizations have been able to contribute to and shape CERIS in meaningful ways, increasing ownership of, commitment to and involvement with the different aspects of the organization.

"The short version [of my motivation to stay involved] I guess would be, there were a lot of opportunities to shape the way CERIS developed..." (Interviewee \#7) 
A new governance structure and participating in the reorganization of CERIS could potentially generate individual and institutional involvement. The role of leadership was identified as essential to renewal efforts of a CERIS-like institution

\subsubsection{Shared and Supported Leadership}

Leadership has and will play a vital role in any continuation of CERIS activities. The organization excelled when the collaborative partnership governance structure yielded shared leadership and supported leaders working to advance the organization's goals. Shared leadership refers to a talented group of invested individuals from different institutions placing a high priority on their CERIS responsibilities. This includes individuals volunteering significant time and resources to advance the shared agenda. There was however a range of opinions as to whether the process of a renewed CERIS would be driven by an individual leader or group of committed individuals.

"You need a leader, for something like this, you need an entrepreneur who is willing to organize the small group, who is willing to help put in the time, put in the weekends, put in the evenings." (Interviewee \#3)

"I think it's going to need a strong champion and I think, the supporting cast is in place. There are enough people who are supportive, interested and have enough connection and heft in a particular community or constituency that they could help to carry it." (Interviewee \#1)

"...you need the right person, in the right position, in the right time. The right persons, because it's not just one person, it has to be a team effort." (Interviewee \#6)

“...somebody has to, somebodies preferably have to say, they would lead and nobody has. And that's very unfortunate...We need multiple leaders...” (Interviewee \#6) 
Beyond institutional support, CERIS has achieved success as individual faculty have worked and volunteered beyond their institutional responsibilities.

Supported leadership meant that individuals had the commitment of the institutional partners. This includes obtaining the necessary resources from individual institutions to allow faculty to focus on CERIS activities. This could take the form of release time, physical space, stipends, good working relationships with university administration and other contributions as necessary. It also means universities engaging in partnerships and communication with other universities and institutions.

About half of the participants recognized that there are disincentives to participating with CERIS. Disincentives refer to professional costs associated with individuals' involvement in the collaboration. They claimed that CERIS would have more chance for successful sustainability if barriers to participation were removed.

"If you are also going to invest your time and to some degree your professional reputation on more collaborative efforts, you need to have...endorsement of your institution...” (Interviewee \#7)

"Now without the university support, that can't happen! We do jobs. If our employers aren't encouraging us to do certain things, they don't happen." (Interviewee \#6)

Recognizing and rewarding the utilization of research and other forms of expert knowledge can remove disincentives to collaborate. An example of removing a disincentive, is the recognition of creative professional activity (CPA) in promotional decisions for health-related faculty at the University of Toronto. CPA "recognizes that clinicians and other academics may carry on a number of time and energy consuming duties essential to the role of the University in relation to health professionals and the community.” (Department of Medicine - University of Toronto, 2011). Another example 
is SSHRC's deployment of research funds on the preconditions of inter-university and community collaboration as is the case for partnership grants.

\subsection{Summary of Findings}

The institutional reality is that CERIS is dealing with a changing financial situation, the implications include: 1) less formalized channels with government partners; 2) decreased incentives to collaborate; 3) a symbolic and real withdrawal of partners; 4) and a fundamentally different external environment than when CERIS and the Metropolis Project first started.

While there was not consensus from all participants as to whether or not CERIS has the capacity to continue, many insights were gleaned as to the opportunities and challenges for CERIS to renew itself. The main area of dissensus stems from limited funding opportunities in the current environment, i.e. will there be motivation for institutions and individuals to be involved when external incentives to collaborate and institutional capacity are reduced.

With respect to CERIS's organizational capacity to continue in the future, the research explored the following issues;

- Challenges associated with institutional or core funding in the current environment;

- Entrepreneurial opportunities and research funds to engage in knowledge mobilization with a specific focus on convening stakeholders concerned with immigration and settlement in the GTA;

- Reduced incentives to collaborate, necessitating a bottom-up approach to collaboration and gaining institutional buy-in: requiring efforts and organizing driven 
at the individual level by those interested in pursuing policy-driven research. There are challenges associated with this such as; less motivation, less incentive, time commitments and other priorities and responsibilities.

- Organizing around a new set of partnerships at provincial, municipal and local levels and a re-engagement of academic institutions;

- Increasing the communication focus on dynamic, cross-sectorial knowledge mobilization and transfer efforts and engaging the community through various communication channels;

- Embracing cross-sectoral governance opportunities; and

- Relying on shared and supported leadership to advance organizational planning efforts, including a removal of disincentives for active participation.

\subsection{Implications for the Sustainability of Partnership Model}

The experience of CERIS shows there are many benefits and challenges of institutionalizing a partnership. Assessing the organizational capacity of CERIS generates implications for the sustainability of such partnership model, which is an important area of future research.

A partnership model is based on institutional incentives to collaborate. When incentives are present, partners can offer a variety of resources to furthering the agenda of the particular organization. However, the sustainability of such a model is dependant on the existence and accessibility of the incentives for all partner institutions. A lack of institutional incentives challenges the foundation of the model. Further the incentives will be connected to the external political, social and economic environment. There may also be competing incentives for organizations to work independently. Additionally, 
individual and institutional stakeholders will have other commitments and responsibilities not related to the partnership.

Cross-sectoral partnerships rely on the collaboration of different sectors of society and most likely will be generated through unequal resources (i.e. human and financial). A governance structure can provide mechanisms to balance unequal resources and sustain involvement of stakeholders. Partnerships require these mechanisms to manage the challenges associated with unequal power distribution and diverse mandates. 


\section{Conclusions and Recommendations}

\subsection{Recommendations}

The research described in this paper offers to a number of possible recommendations to help create the necessary conditions for the continuation of CERIS:

1. A new institution should shift the focus from generating research to creating a network to deal with needs of individuals, institutions and society helping to bring people together and convening stakeholders involved with immigration and settlement in the GTA or Southern Ontario.

2. The organization should expand its revenue generation to include annual membership fees linked to affiliation, a small percentage of research grants for CERIS-affiliated projects for administrative purposes and completion of a SSHRC Partnership grant to advance the network. Existing CERIS resources/relationships should be used to add value to grant application. Subsidiary funding opportunities should emerge for knowledge mobilization activities.

3. CERIS stakeholders should focus attention to redeveloping relationships with academic institutions at least to the extent that they endorse faculty membership to a renewed CERIS. This can be through recognition of CERIS related efforts in job related promotional decisions. Efforts should be made to engage new affiliates and partners at the provincial, municipal and local level including governments, industry stakeholders and community organizations proposing value-added features of the network. And

4. A new governance structure should maintain cross-sectoral representation. 


\subsection{Conclusion}

This study looks at three types of organizational capacity namely, research and communication, management and governance, and resource acquisition (Mandeville, 2007). It discusses the current environment for knowledge mobilization and describes CERIS organizational capacity in the past, what it has accomplished and some opportunities, challenges and conditions for renewal efforts.

Based on the current funding environment and the institutional reality of CERIS, there was general agreement that a re-articulation of priorities is essential moving forward. However, assessing CERIS's organizational capacity has proved extremely difficult, as there is not general consensus as to what form, if any, a continued CERIS should take. As Wing (2003) suggests, a major challenge in assessing organizational capacity is the level of abstraction that it is spoken about. There was however acknowledgement that CERIS was extremely successful, in that it contributed immensely to all stakeholders and was a valued asset to its community. Further, there was general agreement that aspects of CERIS would continue in the future, whether or not there will be sustained institutional infrastructure. This is supported by SSHRC's emphasis on knowledge mobilization in its strategic plan (2010-2012) and its knowledge mobilization strategy (2009-2011).

The sustainability of the partnership model is based on institutional incentives to collaborate. As Glickman and Sermon (2003) highlight, effective partnerships enhance an organization's ability to function and strengthening of associational networks are critical to success. CERIS's organizational capacity is implicitly connected to its partners and 
stakeholders and the resources they are willing to provide, as capacity is directly linked to how an organization operates as part of the larger system of actors and processes to which they are connected (Chaskin, 2001). The model does not seem to be sustainable without an external driver motivating organizations to work together. So, CERIS's ability for renewal is therefore directly linked to external factors constraining and facilitating its access to resources (Eisenger, 2002). This suggests that if CERIS has the capacity to renew itself as an organization, it is dependent on recognizing who the new formation of partners will be, and the value that can be articulated for each of them. Similar to the emphasis Hall et al., (2003) place on human resources, success of renewal efforts will be determined through individuals' efforts, shared leadership and sustained communication.

It is believed that a GTA-focused organization has the potential to acquire new partners. If CERIS can continue to be a place that can convene various sectors of society and foster a community with the ultimate goal of improving the lives of newcomers, there will be participation.

In its current form CERIS has been successful because of its commitment to knowledge mobilization. It has been successful by including all of its partners in its management and governance and creating the spaces for knowledge exchange at all stages of research, ranging from agenda setting, development, implementation and dissemination. The future of knowledge mobilization seems to have increasing support from various sectors of society in Canada. Despite what form it takes; as an organization or through dispersed activities of its affiliates; CERIS will have a legacy of furthering the use of knowledge, and building capacity around immigration, diversity and settlement. 


\section{Appendix A: Semi- Structured Interview Guide}

\section{Participant/ID\#}

Date:

Script: As you know, CERIS is winding down and what I am interested in, is if you believe CERIS has the capacity to continue functioning without the government funds linked to the Metropolis Project. To that effect, I will ask you some questions around CERIS's organizational capacity.

\section{Questions:}

1. Can you briefly describe your relationship with CERIS?

2. In your opinion, what are some of the motivations for academics to be involved with CERIS?

3. Why did you choose to first become involved with CERIS? What were the benefits? Costs? Probe: Have those conditions changes?

4. Would you be interested in being involved in a future CERIS?

Probe: Do you think other academics or other stakeholders would continue to be involved?

5. How would you describe the quality of relationships between academics, domain leaders, directors, the board?

What about partners i.e. community groups and government officials?

6. What would you say the biggest challenges CERIS has in recruiting academics, and keeping people involved at the organizational level?

7. As CERIS looks towards the future, what is necessary to maintain interest in this process? Probe: What about from the universities?

8. What would committee need to see to continue to be active?

9. What would a future CERIS look like to you? What about it's leadership

10. In your opinion, would academics help with raising funds?

11. What do you think is the greatest value of CERIS? Who are the key beneficiaries

12. In your opinion, is there a future need for CERIS?

13. Deep down, do you think it is going to happen? 


\section{References}

Anisef, P., Rummens, J. A. \& Shields, J. (2007). Diversity and the City: CERIS Research Partnerships and Knowledge Exchange for Policy Impact, Our Diverse Cities, No. 4, Fall, pp. 7-12.

Archer, K. \& Berdahl, L. (2011). Explorations: Conducting empirical research in Canadian political science. ( ${ }^{\text {nd }}$ Edition). Don Mills, ON: Oxford University Press.

Banting, K. (2010). Is There a Progressive’s Dilemma in Canada? Immigration, Multiculturalism and the Welfare State. Presidential Address to the Canadian Political Science Association, Montreal, June 2.

Barman, E. \& MacIndoe, H. (2012). Institutional pressures and organizational capacity: The case of outcome measurement. Sociological Forum, 27(1). 70-94.

Bertrand, F., Picard-Aitken, M., Lecomte, N., Mercure, S., NicNiocaill, B., \& Caruso, J. (2009). Summuative evaluation of the Networks of Centres of Excellence-New initiatives: Final evaluation report. Reported to Social Sciences and Humanities Research Council.

Boswell, C. (2009). The political uses of expert knowledge: Immigration policy and social research. New York: United States. Cambridge University Press.

CERIS (2011). (17 November 2011). Townhall Meeting Report. Retrieved from http://www.ceris.metropolis.net/wp-content/uploads/2011/11/Town-Hall-FinalReport1.pdf

Citizenship and Immigation Canada (2006). Internal review of the Metropolis Project: What are the benefits for CIC? Evaluation Division Research and Evaluation Branch. Retrieved from http://canada.metropolis.net/pdfs/Final\%20Report\%20Metropolis\%20Internal\%20R eview.pdf

Chaskin, R. (2001). Building community capacity: A definitional framework and case studies from a comprehensive community initiative. Urban Affairs Review, 36, 291323.

Clardy, A. (2008). Human resource development and the resource-based model of core competencies: Methods for diagnosis and assessment. Human Resource Development Review, 7, 387 - 410.

Clippingdale, R. (2006). Strategic interviews on the Metropolis Project and on transferring knowledge to policy makers. RTS Services, Retrieved from http://canada.metropolis.net/aboutus/aboutus_e.html 
Citizenship and Immigration Canada (2008). Government of Canada announces new funding for research on immigration and diversity. Retrieved from http://www.cic.gc.ca/english/department/media/releases/2008/2008-01-07.asp

Cohn, D. (2006). Jumping into the political fray: Academics and policy-making. Institute for Research on Public Policy, 7(3). Retrieved from http://www.irpp.org/pm/archive/pmvol7no3.pdf

Crawford, L. \& Nahmias, A. H. (2010). Competencies for managing change. International Journal of Project Management, 28(4), 405- 412.

Cuskelly, G., Taylore, T., Hoye, R., \& Darcy, S. (2006). Volunteer management practices and volunteer retention: A human resource management approach. Sports Management Review, 9, 141-163.

Department of Medicine - University of Toronto Website: http://www.deptmedicine.utoronto.ca/Faculty/CPA_Dossier.htm

Dukeshire, S. \& Thurlow, K (2002). Understanding the Link Between Research and Policy. Atlantic Health Promotion Research Centre. Retrieved from http://www.ruralnovascotia.ca/documents/policy/research\%20and\%20policy.pdf

Eakin, L. (2002). Supporting organizational infrastructure in the nonprofit sector. Background paper for VSI Secretariate.

Eisinger, P. (2002). Organizational capacity and organizational effectiveness among streetlevel food assistance programs. Nonprofit and Voluntary Sector Quarterly, 31, 115-130.

Gatta, M. \& McCabe, K. (2008). The "new” policy partnership: Academic researchers and government officials partnering toward social equity. Equal Opportunities International, 27(2), 129-131.

Glickman, N.J. \& Servon, L.J. (1998). More than bricks and sticks: Five components of community development corporation capacity. Housing Policy Debate, 9, 497-513.

Giordani, P. \& Ruta, M. (2011). The immigration policy puzzle. Review of International Economics, 19(5), 922-935.

Government of Canada - Department of Justice (2001). Immigration and Refugee Protection Act. Ottawa, ON: Canada. Retrieved from http://laws.justice.gc.ca/eng/acts/I-2.5/

Guba, E. \& Lincoln, Y. (2003). Paradigmatic controversies, contradictions, and emerging confluences. In Norman Densizin and Yvonne Lincoln (Eds) The Landscape of Qualitative Research. Thousand Oakes: Sage 
Hall, M.H., Andrukow, A., Barr, C., Brock, K., de Wit, M., Embuldeniya, D., et al. (2003). The capacity to serve: A qualitative study of the challenges facing

Canada's nonprofit and voluntary organizations. Toronto, ON: Canadian Centre for Philanthropy.

Imagine Canada (2006). Investing in Citizens and Communities. A Submission on the Community Nonprofit Sector to the Blue Ribbon Panel on Grants and Contributions under the Federal Accountability Action Plan 2006. Retrieved from http://www.imaginecanada.ca/files/www/en/publicaffairs/final_blue_ribbon_panel_a ug_2006.pdf

Kelly, N. \& Trebilcock, M. (2010). The making of the mosaic: A history of Canadian immigration policy. Toronto: University of Toronto Press.

Keung, N. (2012, February 28). Ottawa axes network of immigration research centres. Toronto Star. Retrieved from http://www.thestar.com/news/canada/article/1138186-ottawa-axes-network-of-immigration-research-centres

Landry, R., Lamari, M., \& Amara, N. (2003). The extent and determinants of the utilization of university research in government agencies. Public Administration Review, 63(2), 192-205.

Mandeville, J. (2007). Public policy grant making: Building organizational capacity among nonprofit grantees. Nonprofit and Voluntary Sector Quarterly, 36,282-300.

Meinhard, A., Foster, M., \& Berger, I. (2003). The Evolving Relationship Between Government and the Voluntary Sector in Ontario. Centre for Voluntary Sector Services. CVSS Working Paper Series. 23, 1-23.

Mesch, D. (2010). Management of human resources in 2020: Outlook for nonprofit organizations. Public Administration Review, Special Issue. 173-174.

Meyer, M. (2010). The Rise of the Knowledge Broker. Science Communication, 32. 118131.

Misener, K. \& Doherty, A. (2009). Case study of organizational capacity in nonprofit community sport. Journal of Sport Management, 23, 457- 482.

Natural Sciences and Engineering Research Council of Canada (n.d.) Website: http://www.nserc-crsng.gc.ca/index_eng.asp

Newborn, T. (2008). Creating nonprofit excellence through capacity building. Nonprofit World, 26(2), 23. 
Paris, R. (2011). Ordering the world: Academic research and policymaking on fragile states. International Studies Review, 13, 58-71.

Piccoli, G. \& Wagner, E. (2003). The value of academic research. Cornell Hospital Quarterly, 44(2), 29-39.

Rummens, J. A. (2012). Creating Spaces: Linking Migration Research with Policy Practice Needs. In Rodriguez-Garcia, D. (Eds), Managing Diversity and Immigration in Quebec and Canada. A Transatlantic Dialogue in the New Age of Migration. Montreal and Kingston (pp .358-380). McGill-Queens University Press.

Shields, J. (2007). Mobilizing Immigration Research for Policy Effect: The Case of CERIS. CERIS Working Paper, 58.

Shields, J. \& Evans, B. (2008). Knowledge Mobilization/transfer, Research Partnerships, and policymaking: Some conceptual and practical considerations. CERIS Policy Matters, 33, 1-14.

Shields, J. \& Richmond, T. (2004). Third Sector Restructuring and the New Contracting Regime: The Case of Immigrant Serving Agencies in Ontario. Centre for Voluntary Sector Services. CVSS Working Paper Series, 24, 1-28.

Social Sciences and Humanities Research Council (2000). Evaluation Metropolis Program: Joint Initiative of Citizenship and Immigration Canada and the Social Sciences and Humanities Research Council of Canada. Retrieved from http://canada.metropolis.net/research-policy/sshrc/metropolis_e.pdf

Social Sciences and Humanities Research Council (2006). Report on the mid-term review of the second phase (2002-07) of the Metropolis Project Canada. Retrieved from http://canada.metropolis.net/research-policy/sshrc/mid_term_May06_Final.pdf

Social Sciences and Humanities Research Council (2007). Metropolis phase 3 (20072012): Annexes A-L memorandum of understanding between Social Sciences and Humanities Research Council and Citizenship and Immigration Canada. Retrieved from http://canada.metropolis.net/pdfs/Annexes\%20A-L\%20Eng.pdf

Social Sciences and Humanities Research Council (2009). SSHRC's Knowledge Mobilization Strategy. Retrieved from http://www.sshrc-crsh.gc.ca/aboutau_sujet/publications/KMbPI_FinalE.pdf

Social Sciences and Humanities Research Council (2010). Framing our Direction: Strategic Plan 2010-2012. Retrieved from http://www.sshrc-crsh.gc.ca/aboutau_sujet/publications/FramingOurDirection_2010-12_final_e.pdf 
Sowa, J., Selden, S. C. \& Sandfort, R. (2004). No longer unmeasurable? A multidimensional integrated model of nonprofit organizational effectiveness. Nonprofit and Voluntary Sector Quarterly, 33, 711-730.

Wing, K.T. (2004). Assessing the effectiveness of capacity-building initiatives: Seven issues for the field. Nonprofit and Voluntary Sector Quarterly, 33, 153-160.

Yin, R. (1990). Case study research: Design and methods. Applied Social Methods Research Series, 5. California: Sage Publications. 